\title{
Erratum to: Impact of breast cancer on anti-mullerian hormone levels in young women
}

\author{
H. I. Su • S. W. Flatt $\cdot$ L. Natarajan • \\ A. DeMichele $\cdot$ A. Z. Steiner
}

Published online: 28 March 2013

(c) Springer Science+Business Media New York 2013

\section{Erratum to: Breast Cancer Res Treat (2013) \\ 137:571-577 \\ DOI 10.1007/s10549-012-2361-5}

Unfortunately in the original publication of the article, author has included the standard deviations for anti-Mullerian hormone $(\mathrm{AMH})$, follicle stimulating hormone (FSH) and inhibin B (inhB) in Table 1. As confidence intervals (CI) are more interpretable for log-transformed data, the correct $95 \%$ CI for each of these three hormones have been given below.
Table 1 Hormone measures of ovarian reserve (geometric mean $[95 \% \mathrm{CI}])$ of breast cancer and healthy participants

\begin{tabular}{lccc}
\hline & $\begin{array}{l}\text { Breast cancer } \\
\text { participants } \\
(N=108)\end{array}$ & $\begin{array}{l}\text { Healthy } \\
\text { participants } \\
(N=99)\end{array}$ & $p$ value \\
\hline AMH $(\mathrm{ng} / \mathrm{ml})$ & $0.66(0.48-0.78)$ & $1.1(0.89-1.38)$ & $<0.001^{\mathrm{a}}$ \\
FSH $(\mathrm{mIU} / \mathrm{ml})^{\mathrm{b}}$ & $7.7(6.0-10.3)$ & $7.3(6.7-7.9)$ & $0.52^{\mathrm{a}}$ \\
$\mathrm{InhB}(\mathrm{pg} / \mathrm{ml})^{\mathrm{b}}$ & $27.7(19.7-38.9)$ & $30.9(27.3-35.5)$ & $0.45^{\mathrm{a}}$
\end{tabular}

\footnotetext{
a Student's $t$ test on log-transformed levels

${ }^{\mathrm{b}}$ Restricted to participants with estradiol levels $<80 \mathrm{pg} / \mathrm{ml}$ (45 breast cancer and 91 healthy participants)
}

The online version of the original article can be found under doi:10.1007/s10549-012-2361-5.

\section{H. I. Su (ه) · S. W. Flatt · L. Natarajan}

Division of Reproductive Endocrinology and Infertility

and Moores UCSD Cancer Center, University

of California San Diego, 3855 Health Sciences Drive \#0901,

La Jolla, CA 92093-0901, USA

e-mail: hisu@ucsd.edu

\section{A. DeMichele}

Center of Clinical Epidemiology and Biostatistics and Abramson

Cancer Center, University of Pennsylvania, 3 West Pavilion,

3400 Civic Center Boulevard, Philadelphia, PA 19104, USA

\section{A. Z. Steiner}

Division of Reproductive Endocrinology and Infertility,

University of North Carolina Chapel Hill, 4001 Old Clinic

Building, Campus Box 7570, Chapel Hill, NC 27599, USA 